\title{
Muscle assessment in healthy teenagers. Comparison to teenagers with low back pain
}

\author{
JC Bernard*, R Bard, A Pujol, A Combey, D Boussard, C Begue and \\ AM Salghetti
}

\author{
Address: Service enfants-adolescents, centre médico-chirurgical de réadaptation des Massues, 92 rue Edmond Locard 69322 Lyon cedex 05, France \\ Email: JC Bernard* - bernard-mpr@cmcr-massues.com \\ * Corresponding author
}

\author{
from 6th International Conference on Conservative Management of Spinal Deformities \\ Lyon, France. 21-23 May 2009 \\ Published: 14 December 2009 \\ Scoliosis 2009, 4(Suppl 2):O4 doi:I0.I 186/I748-7|6I-4-S2-O4
}

This abstract is available from: http://www.scoliosisjournal.com/content/4/S2/O4

(c) 2009 Bernard et al; licensee BioMed Central Ltd.

\section{Objectives}

To describe muscle parameters in healthy teenagers and to compare them with teenagers who have chronic low back pain (CLBP).

\section{Methods}

A comparative study of 276 control teenagers and 51 teenagers who were being treated for CLBP. Both groups had an average of 14.5 years. The control group was made up of teenagers without back pain as well as teenagers who reported some back pain when asked, but who had never had specific treatment. The results of four static tests assessing trunk flexors, trunk extensors, hip extensors and quadriceps endurance were compared statistically. In the control group, the association between a number of clinical measures and back pain were evaluated.

\section{Results}

The two groups were homogeneous in terms of their age, weight, standing height, sitting height and BMI ( $\mathrm{p}>0,05)$. Low back pain was more common in girls, both in the control group (69\% of girls) and in the group with CLBP (78\%). CLBP was associated with a poor endurance strength of the trunk extensors (151 sec in the control group to $105 \mathrm{sec}$ in the CLBP), with hip extensor weakness (140 sec in the control group to $84 \mathrm{sec}$ in the CLBP), and with quadriceps weakness ( $159 \mathrm{sec}$ in the control group to $140 \mathrm{sec}$ in the CLBP $),(\mathrm{p}=0.000)$. No significant difference was found between trunk flexor endurance in the two groups (131 sec in the control group to $133 \mathrm{sec}$ in the CLBP). In the control group, 48 teenagers reported back pain "often", "very often" or "all the time" although no links were found between pain and muscle flexibility (measured with finger-floor distance, heel-cheek distance, and popliteal angle). Only the sitting height was found to be statistically different $(\mathrm{p}=0.003)$ in the control teenagers who reported back pain $(87 \mathrm{~cm})$ related to the ones who did not have pain $(85 \mathrm{~cm})$.

\section{Conclusion}

Sport influences global strength in the lower limbs and changes the ratio of strength in the quadriceps to hip extensors, in favor of the quadriceps. Neither pain nor the ratio of trunk flexors to trunk extensors are modified by sports participation. Trunk extensors, hip extensors and quadriceps endurance is lower in the those with CLBP. 